Loading

The Journal of the Canadian Game Studies Association

\title{
Foreword: To All the Animals We've Crossed Before
}

\section{Rainforest Scully-Blaker and Emily Flynn-Jones}

Volume 13, Number 22, 2020

Animal Crossing Special Issue

URI: https://id.erudit.org/iderudit/1075259ar

DOI: https://doi.org/10.7202/1075259ar

See table of contents

Publisher(s)

Canadian Game Studies Association

ISSN

1923-2691 (digital)

Explore this journal

Cite this document

Scully-Blaker, R. \& Flynn-Jones, E. (2020). Foreword: To All the Animals We've Crossed Before. Loading, 13(22), 1-6. https://doi.org/10.7202/1075259ar

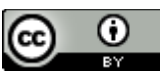

This document is protected by copyright law. Use of the services of Erudit (including reproduction) is subject to its terms and conditions, which can be viewed online.

https://apropos.erudit.org/en/users/policy-on-use/
This article is disseminated and preserved by Érudit.

Érudit is a non-profit inter-university consortium of the Université de Montréal, Université Laval, and the Université du Québec à Montréal. Its mission is to promote and disseminate research.

https://www.erudit.org/en/ 


\section{Foreword: To All the Animals We've Crossed Before}

\author{
Emily Flynn-Jones \\ CEO, Killjoy Games \\ hello@killjoygames.fun
}

\author{
Rainforest Scully-Blaker \\ $\mathrm{PhD}$ Candidate, UC Irvine \\ fscullyblaker@gmail.com
}

Welcome, dear reader, to this selection of essays on Nintendo's Animal Crossing series. This was one of those special issues that came into being for the simple reason that both of us felt that we needed it to exist. It involved a lot of hard work and planning on our part, but we were certainly not alone. Our authors, of course, whose pieces are teased in more detail below, all presented us with intriguing, high-quality essays and have diligently polished them to a mirror shine. The sheer quality of this work would of course not have been possible without the efforts of our generous and discerning peer-reviewers. Finally, we would certainly be remiss to not mention the journal itself, without which this project would not even have gotten off the ground. So while this foreword is our chance as editors to throw our voices into the conversations contained within this issue, we wanted to ensure that we acknowledged all the people whose labour made what follows possible since we strongly feel that this has been much more than a pragmatic exercise in producing scholarly deliverables.

We come to this project as scholars and designers of games, but also as fans of the Animal Crossing series. The pursuit of something called academic rigour often requires that we put aside our investment or intimacies with an object in order to study it from a 'critical distance' but we are firm believers in both critiquing what you love and celebrating that love in your analysis. Animal Crossing means something to us. It means many things to us and it clearly means a lot of things--and different things--to different people.

It is in that spirit that we have devoted the 'analytic' portion of this foreword to sharing anecdotes about why we love Animal Crossing. In sharing some of the ways this series has left a lasting impact on us, we hope to convey why many consider it to be not only worthy of hundreds of hours of our time (to play, to think about, to write about) but also why we think it is worth your time to read about it in this special issue.

\section{Emily and the Stalk Market}

Once upon a summer 2013 I moved to a new country. I knew almost no one but armed with a pretty-in-pink 3DS and a copy of New Leaf, this socially awkward Doctor quickly found a community bonded in play: co-present, virtual and in ALL MIGHTY SPREADSHEETS.

Our play was serious business. We each tracked our stalk markets religiously logging in to a spreadsheet at least twice a day to enter the price of turnips in our little towns. If someone had an economic spike, we would arrange a time to visit their town. This could involve some tricky logistics since if you were out you'd have to find stable wifi and with only 3 wifi slots for the system you might need to delete one connection and create a new one. If you were at work you might have to surreptitiously launch the game and open your gates leaving the console open 
somewhere until everyone confirms they've been in town and made the trade. If this was in the morning there could be a rush to make it all happen before the prices change at noon and you potentially lost money.

The act of selling had its rhythms and rituals. Each of us being a cuter version of Gordon Gecco about this part of the game, we bought huge crops of turnips every Sunday. Our pockets would literally be overflowing. This glut made for some irritation when it came to selling since you'd have to do a lot of back-and-forth picking up your turnips, taking them to a town, selling them, going home, dropping off your bounty and collecting more turnips to do it again and again until rolling in dough, much of which you immediately handed over to a Nook. We also had an unspoken rule that you left a present or a sweet little note on the village message board for the person whose town you sold your goods in.

One particular exchange took place at a wedding five of our group were attending. Turnips were selling for more than 600 Bells in my town of Jumpkins (this is A LOT and no I am not going to explain the name). We all giddily gathered together establishing a local connection so everyone could board the train to Jumpkins and make some money. It is a thoroughly romantic memory for me and my Animal Crossing crew continues to make new memories and spreadsheets in New Horizons (See Figure 1).

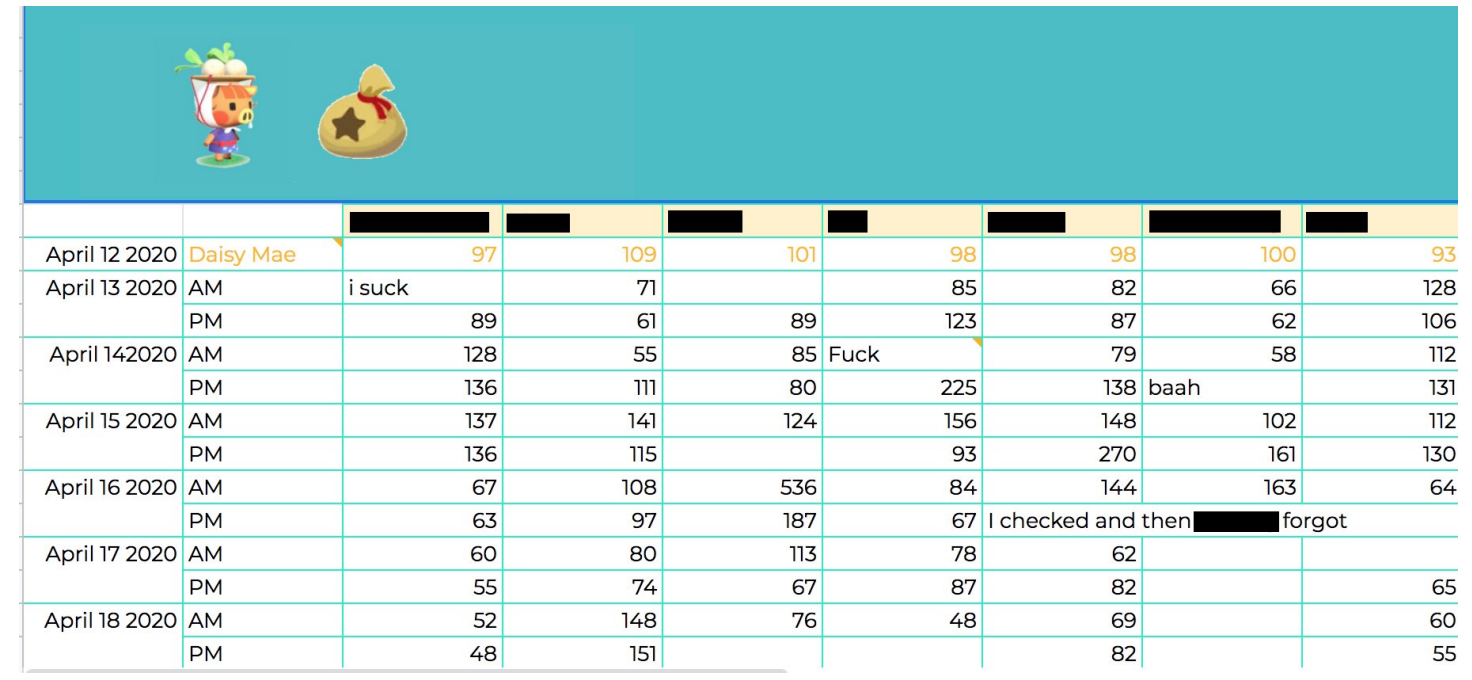

Figure 1: The latest in turnip-tracking technology

\section{Rainforest and Bones}

I'm a child of the 90s, a time when the nature of coming-of-age stories was beginning to shift. Gone were the days of a bunch of kids walking along some train tracks or having heart-to-hearts in detention and in their wake came gravely wounding burglars with home appliances and Shakespeare plays set in American high schools. Maybe this says something about me, but much of my sentimental education came from the virtual worlds of video games, Animal Crossing chief among them. 
I have many fond memories of playing the Gamecube version in my youth, but none top the story of Bones. A childhood friend and I each had a copy of the game and so whenever we had sleepovers, we would take turns visiting each other's towns. We'd trade fruits, patronize the shops, and chat with the locals. One such inhabitant of my friend's town was Bones, a white dog with a brown spot on one eye who wore a brown and yellow top (See Figure 2). His home was decorated somewhat oddly, with an oversized alarm clock in the middle of the room and a Newton's cradle on the floor, but no bed (See Figure 3).
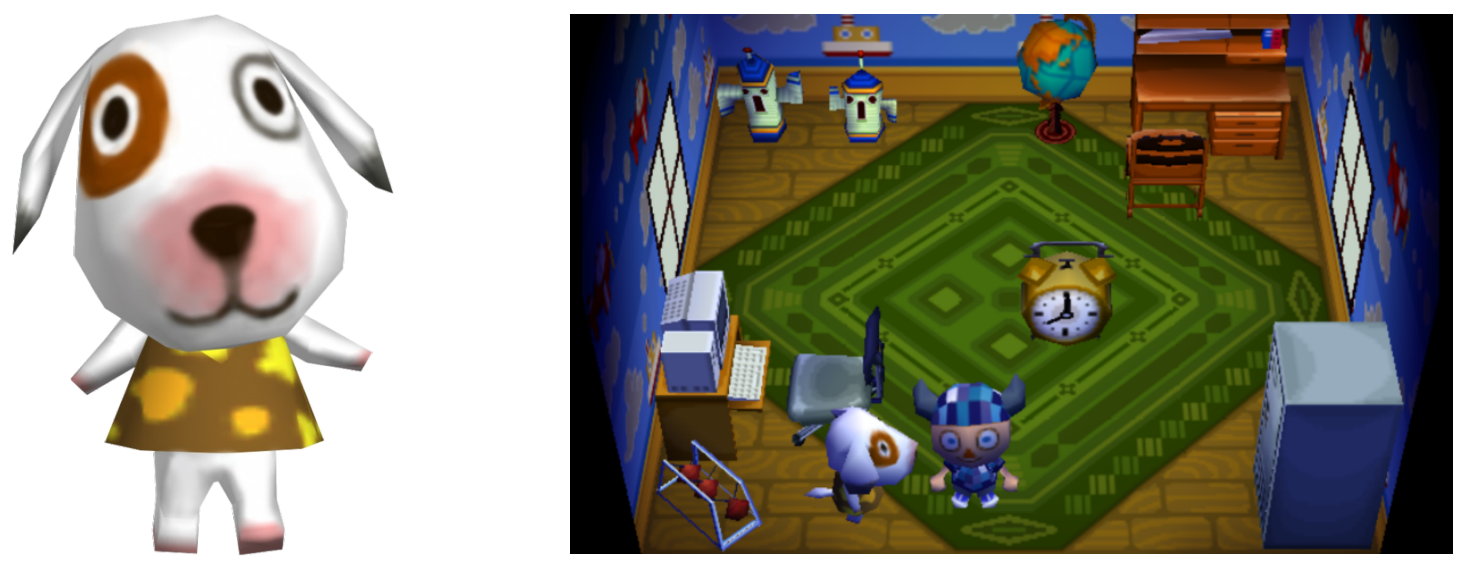

Figures 2 and 3: The dog himself and his questionable taste in interior decorating

Above all, though, Bones was an exceptionally nice dog, a real salt of the earth pooch. He was my friend's favourite villager bar none. Alas, in Animal Crossing just as in life, time marches on and even best of chums must sometimes be parted. And so, one day when my friend boarded the bus to school and sat down next to me, I could tell something was amiss. He had some heavy news: the night prior, Bones had confided in him that he planned to move away. I offered my condolences since, in those days, once a villager had told you they were moving, there was nothing you could do. One day they'd be gone without a trace, back into the aether of the game's code.

\section{Unless.}

If you or a friend had a memory card with a separate village hooked up to the console at the same time, your villager's wanderlust could take them to that other town instead. Not wanting Bones to end up in parts unknown, my friend told me, with such gravitas that you might think he was asking me to take care of a real dog he had raised from birth, that he wanted me to have Bones move into my town. My 10-year-old heart definitely skipped a beat. I nodded silently and let him say his piece, but inside I was stunned. He asserted that he would not play Animal Crossing until we next had a sleepover, no small sacrifice to be sure. That way, we could guarantee that the spotted dog would transfer over to my village and so still be in my friend's life. I can still remember the how genuinely touched I felt in that moment and while that memory card and that village are long gone, the memories of playing with my friend and of welcoming Bones into my village are not. 
4 Loading... The Journal of the Canadian Game Studies Association

Vol 13(22): 1-6

http://loading.gamestudies.ca

\section{The (Special) Issue at Hand}

So much for how we came to Animal Crossing and to this issue, it is time to discuss the papers themselves. There are themes such as conspicuous consumption and community woven throughout this collection, but we have still managed to organize our seven contributions into three sections based on other similarities:

\section{One Animal's Trash:}

The issue begins with two radically different takes on perhaps the most celebrated--and criticized--aspect of Animal Crossing: collecting. The 479-page tome that is the official New Leaf game guide is an indicator of just how much there is to collect in the game from furniture and bugs to bells and villagers. Under this umbrella, Andrew Remington Bailey uses media archaeology methods and the mechanics of the in-game museum to think through emerging videogame curation and preservation practices. Meanwhile, for Jared Hansen it's not just what one accumulates, but what one throws away. His paper investigates what players choose to dispose of and how digging through that digital debris can tell us a great deal about the culture that got rid of them.

\section{Creature Comforts}

Of course, Animal Crossing games are more than collect-a-thons. As our personal stories of Animal Crossing suggest, the game is one with which we have formed deep, emotional ties and we're by no means alone in feeling this way. These papers offer thoughtful insights into the ways that affect plays into and is played out by games in the series. First, Kyle M. Bohunicky discusses the practice of letter writing [...] Sometimes even the most lengthy correspondences must end as Anna Maria Kalinowski shows in her paper on goodbyes [...] Finally, Gracie Lu Straznickas turns the affective lens selfward in a powerful autoethnographic account of her relationship(s) with and within Animal Crossing while living with chronic pain and illness.

\section{The Cult(ure) of Animal Crossing}

Although this special issue is focused on a specific series of video games, this does not mean that all our pieces deal exclusively with virtual worlds and practices. Collecting and Affect are fundamental to the gameplay but these logics seep into the real world as well. Concluding this issue we have scholars who remind us that games like Animal Crossing both produce and are produced by the cultures in which they exist. Representation matters. How we frame actions and what we invite players to do in games matters. Design choices contain values and these articles take deep but differently oriented dives into the cultural significance of the Animal Crossing series. Miguel Cesar puts Animal Crossing in the context of contemporary Japan and an increasingly anti-social and isolated society while Emma Vossen brings western millennial energy to trouble the economy of the games.

\section{Adendum: New Horizons and the Search for Sunnier Shores Amidst COVID-19}

Peeling back the curtain a bit, when we began writing this foreword (in early March of 2020), the 
5 Loading... The Journal of the Canadian Game Studies Association

Vol 13(22): 1-6

http://loading.gamestudies.ca

world was a very different place. The number of sleeps until the latest release in the series, Animal Crossing: New Horizons, was getting tantalizingly low and beyond the tumult of current events in a 24-hour news cycle, life was largely business as usual. By the time that the game released, terms like "social distancing", "self-isolation", and of course "coronavirus" had become all-too familiar, all-too quickly.

Suddenly, a game about purchasing a "Deserted Island Getaway Package" and beginning a new life among talking animals took on new significance in popular culture and regimes of self-care. In your daily life, depending on where you lived, you were likely afraid to leave your home for too long, and were often actively advised against going outside for anything that was not essential. Contact with friends and family who did not live with you, especially those who were notably susceptible to complications from COVID-19, was equally discouraged and so even those essential trips to buy food were likely to cause stress and anxiety in even those leastaffected. And, as both editors of this special issue happened to experience first-hand, air travel was suddenly a mad scramble for those working, living, or visiting abroad to get back to whatever home was safest or most in need of their support.

Meanwhile, in one's Animal Crossing life, a normal day consists of strolling casually to the shops, chatting with each and every villager on the way. At first, there is never that much in stock, but every day brings the possibility of discovering a new way to decorate your home and indeed the whole island. Your neighbours are always happy to see you and even happier to chat or to give and be given gifts. And while, yes, you have taken out a substantial loan from a kindly tanooki to afford all of this, there is no deadline to pay him back, and no interest racking up your debt. Once you finish with these daily routines, you can hop on a seaplane and fly to other islands where you and your human friends can achieve a virtual proximity that does not break quarantine rules.

The game had scarcely been out for a month and we were already seeing people go on dates, hold wedding ceremonies, and even build memorials in the Animal Crossing world. The apparent escapist fantasy of living on a tropical island was transformed into an escapist reality that seized by many in those moments where they would otherwise be anxious and alone.

The flipside to all of this is that Animal Crossing: New Horizons is a product, a piece of software sold to consumers by Nintendo for use on their proprietary piece of hardware, the Nintendo Switch. Whether due solely to Animal Crossing or not, once quarantine began, Nintendo had to rush the production of more Switches to meet the sudden demand of droves of people left home and in need of distraction. New Horizons itself since has sold more units than every other game in the series combined. In-game, with the players have begun charging admission for strangers to come to their island when turnips are being bought at high prices or some desirable piece of furniture is on sale or a popular villager is looking for a new home. To better organize this, a community marketplace has been created, called Nookazon. While the exact implications of these things (and indeed of the pandemic itself) remain unknown to us as we continue to live through it, it is clear that even in times of crisis when many are struggling, capital finds ways to do well. 
6 Loading... The Journal of the Canadian Game Studies Association

Vol 13(22): 1-6

http://loading.gamestudies.ca

Meanwhile, people continue to try and get by while hoping for an arrival at some sort of normal. In the context of game studies, at least, we expect that there will be plenty of scholarship discussing play in the time of COVID-19. We would not be surprised if some of it will directly tie to Animal Crossing: New Horizons in some of the ways we have mentioned here and in many others that we have not. We hope that this issue is of use to those who plan to write it and for all others who happen to find us, scholars or not.

Thanks much for reading! 